\title{
Study on the Development of China Solar Energy Technology Based on Patent Analysis
}

\author{
Xia Yongqi, Hou Yuanyuan, Lv Huaqiao, Huang Yurong \\ Beijing Municipal Institute of Science and Technology Information, Beijing, China \\ xiayq@bjstinfo.com.cn, houyuanyuan@outlook.com, huaqiao@eyou.com, hyrta@126.com
}

\begin{abstract}
Patent is a special type of technology document. All these special features of patent documents make them a valuable source of knowledge regarding technology development. In paper, the China Patent Abstract Database was chosen; solar energy technology patents between 1985 and 2012 were collected. Solar energy technology patents were analyzed from the patent applications, technology sub-class, and correlation analysis, respectively. The patent trends of solar energy technology were also discussed.

Index Terms - Solar Energy, Patent Analysis, Correlation Analysis.
\end{abstract}

\section{Introduction}

Patents are a wide field, where techniques, products, applications and legal considerations are very mixed. Most of the time, this is also a field often dedicated to the industrial users and, for example, the academic community do not cite patents very often. Nevertheless, patents are a unique source of information since most of the data and information published in patents are not published elsewhere. [1] A patent is a special type of technology document. As an open source of knowledge, it contains rich content regarding technology innovations and is accessible by the general public. Most countries have adopted similar patent systems. A large number of patents are issued every day and collected and published systematically worldwide. The patent documents are also strictly structured, providing standardized fields. All these special features of patent documents make them a valuable source of knowledge regarding technology development. Analyzing patents issued till date reveals a lot of hidden information about various factors such as: current research trends in particular areas, prolific companies / organizations involved in research work, similar patents, patent portfolio of organizations, infringement analysis, etc.[2-5]

Since the oil crises of the 1970s, the world has increasingly paid attention to the development and diffusion of alternative energy sources in order to reduce dependency on fossil fuels. During the oil crises, the primary focus was on increasing self-sufficiency with respect to energy sources. By the 1990s, environmental concerns had taken the forefront, leading to a new phase in the development of alternative energies. This new phase coincided with an increase in the number of patent applications as well as the number of applicants involved in developing alternative energy technologies, particularly from 2000 onwards, when a rapid acceleration in patent activity took place. People have turned increasingly to alternative energy sources as an answer to the environmental, political, and social problems linked to fossil fuel use. Alternative energy sources are broadly defined as energy sources that do not cause or limit net emissions of carbon dioxide and thus largely avoid the environmental impacts associated with the combustion of fossil fuels.[6-8]

Solar energy is an important alternative energy. Solar energy production can be divided into two types: solar thermal energy and photovoltaic power production. In the former case, heat captured from the sun is used for residential heating or industrial processes or for thermal power generation. Technologies involved in solar thermal energy production include solar heat collection, heat storage, systems control, and system design technologies. In the latter case, specially adapted semiconductor devices are used to convert solar radiation into electrical current. Related technologies include solar cell design, storage battery, and power conversion technologies. [9-12] Solar energy is very important for the development of China's renewable energy industry. We should analysis of trends in technological innovation in order to design appropriate policies for the promotion of solar energy. Therefore, the objective of this paper is providing an overview of the technologies development trends of solar energy in China through patent analysis method.

\section{Patent Analysis}

With the above goals in mind, we begin our analysis of patents by firstly gathering the data which we plan to analyze i.e. the patents. For the data gathering process, we spider the China Patent Abstract Database website, looking for patent pages. Some keywords were used to identify relevant records in the databases. In this research, we collected the solar energy patent applications published from 1985 to 2012. Longitudinal evolution analyse of the number of patent applications was conducted using the data collected from the previous records. IPC correlation analysis was conducted using the data collected from the patent records, where we have created correlation maps to identify the most important technical topics in solar energy. In this paper, we use Excel and Ucinet software. 


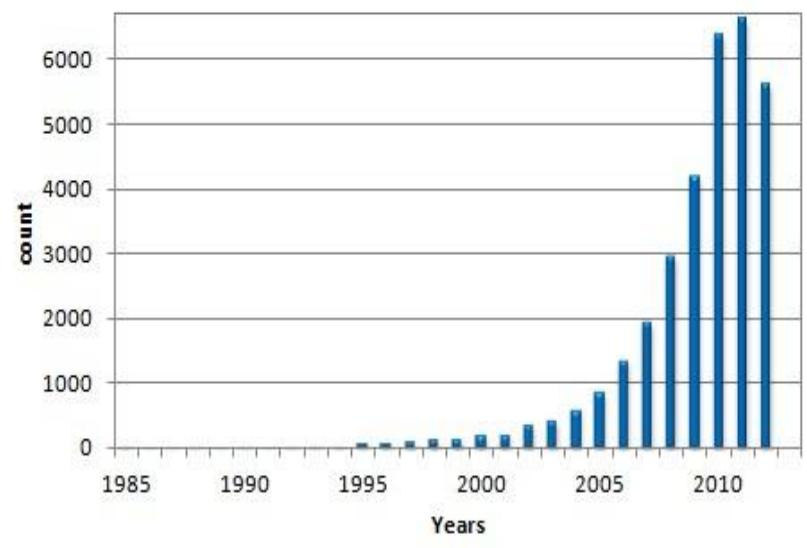

Fig. 1 The numbers of solar energy patent applications of China

The total number of solar energy patent applications per year from 1985 to 2012 is shown in Fig. 1. The solar energy patent appeared in 1985. From 1985 to 1994, the number of patents is in a relatively low number. From 1995 to 2005, the number of patents began to increase. Since 2006, patent activity with respect to solar energy technologies has begun gathering speed and has experienced a continuous increase until the present, with a peak in the number of applications reached in 2011. Due to the special nature of patent data, 2011 and 2012 data were incomplete, the number of patents of 2012 may be more than 2011 .

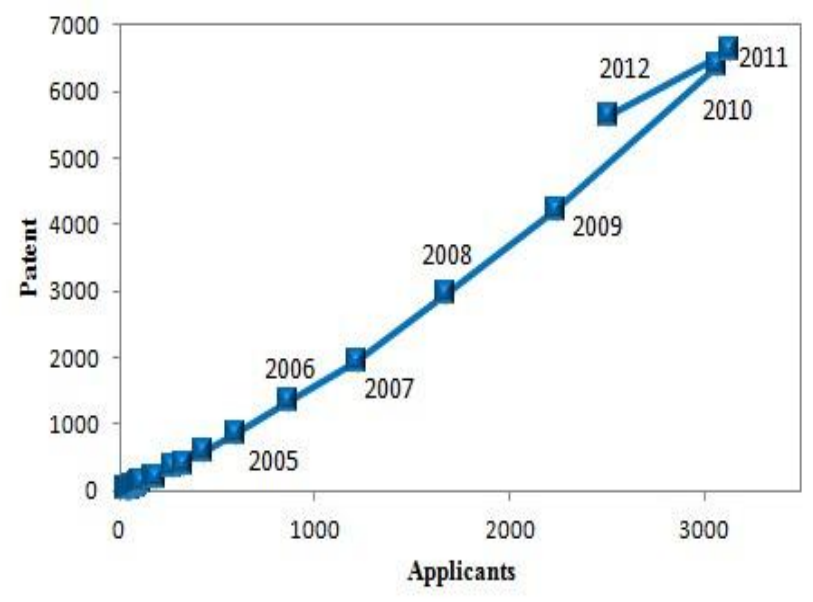

Fig. 2 Technology life cycle of solar energy patent

Fig. 2 shows the technology life cycle of solar energy patent in China. From 1985 to 2005, the number of patents and the number of patent applicants is in a relatively low number. Since 2006, the number of patents and applicants has increased rapidly. By 2010, the number of patents and applicants is in a relatively high number. As mentioned above, 2011 and 2012 data were incomplete. Overall, solar energy technology has entered a period of growing.
TABLE I Ten largest corporate solar energy patent applications

\begin{tabular}{|c|l|c|}
\hline Rank & Assignee Name & Patent \\
\hline 1 & Trina Solar & 283 \\
\hline 2 & Zhejiang University & 248 \\
\hline 3 & Shanghai Jiao Tong University & 215 \\
\hline 4 & Foxconn Technology Group & 200 \\
\hline 5 & Beijing Hikeen Technology Co. Ltd. & 189 \\
\hline 6 & Mitsubishi & 183 \\
\hline 7 & Sharp Corporation & 171 \\
\hline 8 & Jifu New Energy Technology (Shanghai)Co. Ltd. & 167 \\
\hline 9 & Tsinghua University & 165 \\
\hline 10 & Canon Inc. & 165 \\
\hline
\end{tabular}

The top ten applicants who applied for solar energy related patents were shown in Table I. The patent applicants include some well-known companies and institutions like Trina Solar, Zhejiang University, Shanghai Jiao Tong University, Foxconn Technology Group, Mitsubishi, Sharp Corporation, Tsinghua University, Canon Inc. and so on. Trina Solar ranked first with 283 patents, followed by Zhejiang University (248 patents) and Shanghai Jiao Tong University (215patents).

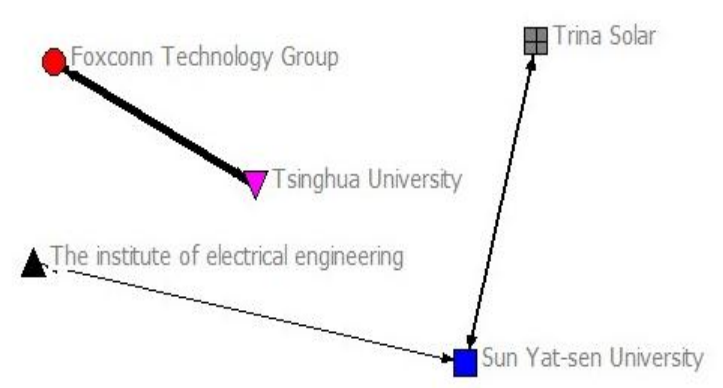

Fig. 3 The co-relationship diagram of corporate

Fig. 3 shows the co-relationship diagram of corporate. Foxconn Technology Group and Tsinghua University have very good cooperation relationship. Sun Yat-sen University and Trina Solar established close cooperation relationship in some areas. Similarly, Sun Yat-sen University and the institute of electrical engineering have cooperation relationship. Overall, the cooperation is weak between the companies in solar energy technology areas.

The International Patent Classification (IPC) class was used to indicate technology fields. In the data (Table II), H01L31/18 (Semiconductor devices sensitive to infra-red radiation, light, electromagnetic radiation of shorter wavelength, or corpuscular radiation and specially adapted either for the conversion of the energy of such radiation into electrical energy or for the control of electrical energy by such radiation; Processes or apparatus specially adapted for the manufacture or treatment thereof or of parts thereof;) ranked first. And H02N6/00 (Generators in which light radiation is directly converted into electrical energy) ranked third. At obviously, photovoltaic power has developed rapidly with 
active government support policies, reductions in costs, and improvements in technology. The ratio of patent applications filed for photovoltaic cells and modules relative to photovoltaic systems is high. At present, such solar cells are produced using amorphous silicon, poly-crystalline silicon, copper-indium-gallium diselenide, and cadmium telluride. Nanotechnologies are increasingly gaining ground in solar cell research, for instance, to produce dye-sensitized solar cells or multi-junction thin-film solar cells.

In addition, F24J2/46 (Component parts, details or accessories of solar heat collectors) ranked second. The majority of applications filed for solar thermal technologies related to the collection of thermal energy, one of two major components of solar thermal power generation along with energy storage. A major barrier to the development of solar thermal technologies is the high initial investment required for their installation, which exceed the costs for other power generation technologies by a significant margin. Currently, research and development efforts into solar thermal technologies are focusing on solar thermo-chemical systems and low temperature solar thermal technologies.

TABLE II Top ten technology fields based on the IPC class

\begin{tabular}{|c|c|c|c|}
\hline Rank & IPC & Class Name & Number \\
\hline 1 & H01L31/18 & $\begin{array}{l}\text { Processes or apparatus specially } \\
\text { adapted for the manufacture or } \\
\text { treatment of these devices or of parts } \\
\text { thereof (Semiconductor devices } \\
\text { sensitive to infra-red radiation, light, } \\
\text { electromagnetic radiation of shorter } \\
\text { wavelength, or corpuscular radiation } \\
\text { and specially adapted either for the } \\
\text { conversion of the energy of such } \\
\text { radiation into electrical energy or for } \\
\text { the control of electrical energy by such } \\
\text { radiation) }\end{array}$ & 4970 \\
\hline 2 & $\mathrm{~F} 24 \mathrm{~J} 2 / 46$ & $\begin{array}{l}\text { Component parts, details or accessories } \\
\text { of solar heat collectors }\end{array}$ & 2684 \\
\hline 3 & $\mathrm{H} 02 \mathrm{~N} 6 / 00$ & $\begin{array}{l}\text { Generators in which light radiation is } \\
\text { directly converted into electrical energy }\end{array}$ & 2548 \\
\hline 4 & H01L31/042 & $\begin{array}{l}\text { including a panel or array of } \\
\text { photoelectric cells, e.g. solar cells }\end{array}$ & 2116 \\
\hline 5 & H01L31/048 & encapsulated or with housing & 1430 \\
\hline 6 & H01L31/0224 & Electrodes & 1355 \\
\hline 7 & $\mathrm{H} 02 \mathrm{~J} 7 / 00$ & $\begin{array}{l}\text { Circuit arrangements for charging or } \\
\text { depolarising batteries or for supplying } \\
\text { loads from batteries }\end{array}$ & 1251 \\
\hline 8 & H01L31/04 & adapted as conversion devices & 1124 \\
\hline 9 & $\mathrm{~F} 24 \mathrm{~J} 2 / 00$ & $\begin{array}{l}\text { Use of solar heat, e.g. solar heat } \\
\text { collectors }\end{array}$ & 1042 \\
\hline 10 & H01L31/052 & $\begin{array}{l}\text { with cooling, light-reflecting or light- } \\
\text { concentrating means }\end{array}$ & 1003 \\
\hline
\end{tabular}

Correlation analysis is a useful method for discovering interesting relationships hidden in large data sets. The uncovered relationships can be represented in the form of association rules or co-occurrence graphs. [13] An event map, a sort of co-occurrence graphs, is a two-dimension undirected graph, which consists of event clusters, visible events, and chances. [14] An event cluster is a group of frequent and strongly related events. The occurrence frequency of events and co-occurrence between events within an event cluster are both high. Recently, the social network analysis is a commonly used method. Social network analysis is the methodical analysis of social networks. Social network analysis views social relationships in terms of network theory, consisting of nodes (representing individual actors within the network) and ties (which represent relationships between the individuals, such as friendship, kinship, organizational position, sexual relationships, etc.). These networks are often depicted in a social network diagram, where nodes are represented as points and ties are represented as lines. [15-16] Social network analysis has emerged as a key technique in modern sociology. It has also gained a significant following in biology, communication studies, economics, geography, and information science. [17-20]

In this study, the correlation analysis and IPC data will be adopted to generate association diagrams. The patents of solar energy is classified by IPC code and selected via the number of appearing times of every specific IPC code. Every patent will be assigned to a specific category according to its IPC code and may be assigned to several categories if its IPC field contains more than one code. Meanwhile, the number of patents for an IPC category will be counted for showing its occurrence frequency. Based on a threshold setting (e.g., 10 was set for this study) on the number of patents in an IPC category, a certain number of the leading IPC categories will be selected and then be utilized to generate the correlation diagrams. The IPC correlation diagrams for solar energy patent applications are used to visualize the major IPC classification. We used the Ucinet (Windows software for analyzing social network data) to analyze of solar energy patent IPC data. A correlation map has two components: the point, and the lines. The width of line represents the degree of association.

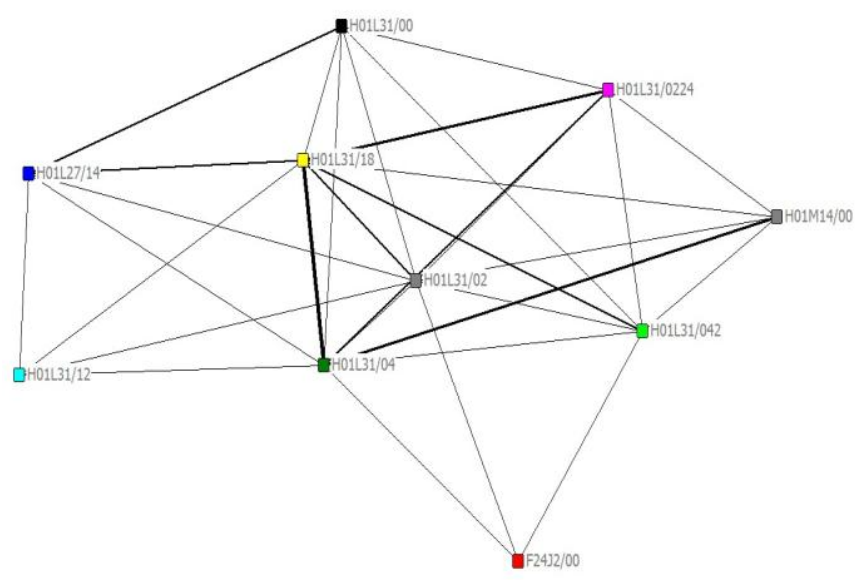

Fig. 4 The IPC correlation diagrams for solar energy patent applications from 1985 to 2005

Fig. 4 shows the correlation for the solar energy patent from 1985 to 2005. As shown, there is some correlation between the ten areas of solar energy technology, such as H01L31/18, H01L31/04, H01L31/042, H01L31/0224, 
H01M14/00, H01L27/14, F24J2/00, H01L31/00, H01L31/02, and H01L31/12. This time period the number of patents is less, so there is no strong correlation between the various technical fields. The behavior of the application cluster around one of the main areas of technology has not yet appeared. Technology development prospects are uncertain.

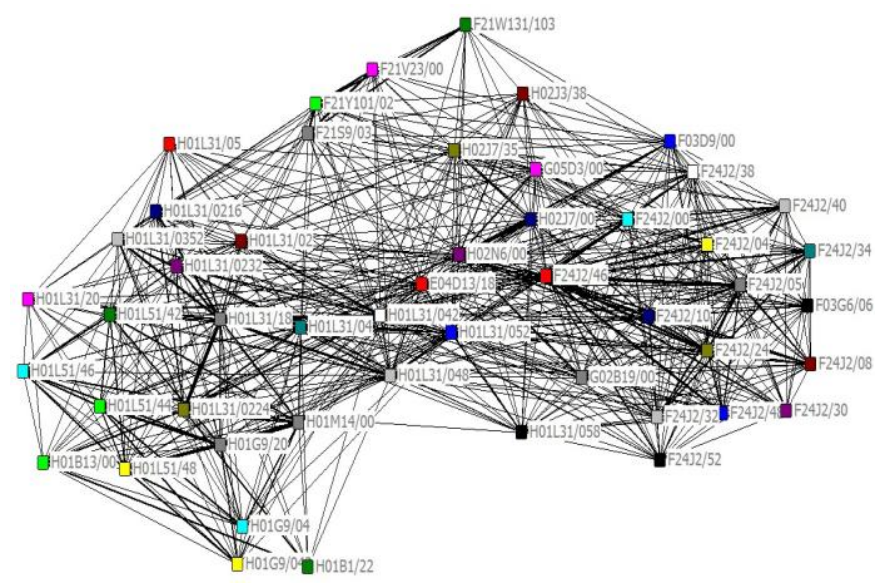

Fig. 5 The IPC correlation diagrams for solar energy patent applications from 2006 to 2012

From 2006 to 2012, the field of solar energy technology associated behavior occurred significant changes, as shown in Fig. 5. There is a strong correlation between H01L31/18 (Processes or apparatus specially adapted for the manufacture or treatment of these devices or of parts thereof), H01L31/042 (including a panel or array of photoelectric cells, e.g. solar cells), H01L31/048 (encapsulated or with housing) and H01L31/0224 (Electrodes).Overall, H01L31/18, H01L31/042, H01L31/048 and H01L31/0224 were the center of solar energy technology field, surrounded by numerous technical fields. This shows that solar energy technology is relatively mature.

\section{Conclusions}

The solar energy patent applications have been evaluated by using the China Patent Abstract Database. Solar energy technology patents are analyzed deeply from the total amount of patent applications, technology sub-class, and association analysis, respectively. From 1985 to 2005, the number of patents and the number of patent applicants is in a relatively low number. Since 2006, patent activity with respect to solar energy technologies has begun gathering speed and has experienced a continuous increase until the present, with a peak in the number of applications reached in 2011. The top technology field (represented by IPC class) was H01L31/18 (Processes or apparatus specially adapted for the manufacture or treatment thereof or of parts thereof). The correlation diagrams show that H01L31/18, H01L31/042, H01L 31/048 and H01L31/0224 were the center of solar energy technology field, surrounded by numerous technical fields. Nowadays, the solar energy technology is relatively mature.

\section{References}

[1] Dou H., Leveillé V., Manullang S., Dou JM., "Patent analysis for competitive technical intelligence and innovative thinking". Data Science Journal, 4(31), pp.1-29, 2005.

[2] Dong Fei, Zhu Donghua, Ren Zhijun, Xie Fei, "Patent Analysis Method and Demonstration Based On Patent Map". Journal Of The China Society For Scientific Andtechnical Information, 26(3), 2007.

[3] Liu Huancheng, "The Function of Patent Information on Analysing Rivals". Information Science, 19(4), 2001.

[4] Byung-Un Yoon, Chang-Byung Yoon, Yong-Tae Park, "On the Development and Application of a Self-organizing Feature Map-based Patent Map". 04, 2002.

[5] Shivraj, Anant, "Patent Mapping Technology in Patents". 02, 2004.

[6] Dora Marinova, "Renewable Energy Technologies in Asia: Analysis of US Patent Data". Second International Association for Energy Economics (IAEE) Asian Conference: Energy Security and Economic Development under Environmental Constraints in the Asia-Pacific Region, pp.193-204.

[7] Commission of the European Com-munities, "White Paper for a community strategy and action plan: energy for the future: renewable sources of energy", Brussels, 1997.

[8] Kim, H.J and Oh, T.H. "New Renewable energy Development Policy of EU”. KIEP World Economy, KIEP (Korea Institute for International Economic Policy), 2006.

[9] Vincenzo B., Alberto C., Margherita V. "Photochemical Conversion of Solar Energy". ChemSusChem, 1, 2008.

[10] Zekai Ş., "Solar energy in progress and future research trends". Progress in Energy and Combustion Science, 30,2004.

[11] D.Kraemer, L.Hu, A.Muto, X Chen, G.Chen, M.Chiesa, "Photovoltaicthermoelectric hybrid system:A general optimization methodology". 2008.

[12] Meng Hao, Chen Yingian, "The Present Situation and Its Countermeasures for Solar Energy Utilizing Technology in China". Forum On Science And Technology In China. 5, 2009.

[13] Tan P.N., Steinbach M., Kumar V., "Introduction to Data Mining". Addison Wesley, 2006.

[14] Ohsawa Y., Benson N.E., Yachida M., "KeyGraph: Automatic Indexing by Co-Occurrence Graph Based on Building Construction Metaphor", Proceedings of the Advanced Digital Library Conference (IEEE ADL), 1998.

[15] Pinheiro, Carlos A.R., "Social Network Analysis in Telecommunications." John Wiley \& Sons. pp. 4, 2011

[16] D'Andrea, Alessia et al. "An Overview of Methods for Virtual Social Network Analysis". In Abraham, Ajith et al. Computational Social Network Analysis: Trends, Tools and Research Advances. Springer. p. 8. 2009.

[17] Linton Freeman, "The Development of Social Network Analysis", Vancouver: Empirical Press, 2006.

[18] De Nooy, "Fields and networks: Correspondence analysis and social network analysis in the framework of Field Theory", Poetics, 31, pp.305-327, 2003.

[19] Kadushin, C. "Understanding social networks: Theories, concepts, and findings". Oxford: Oxford University Press, 2012.

[20] Hanneman Robert A., Riddle, Mark "Concepts and Measures for Basic Network Analysis". The Sage Handbook of Social Network Analysis. SAGE. pp. 364-367, 2011. 